\title{
LA PROMOCIÓN DE SOLUGIONES TECNOLÓGICAS PARA LA DEFENSA DE LOS DERECHOS HUMANOS
}

\section{THE PROMOTION OF TECHNOLOGICAL SOLUTIONS FOR THE DEFENSE OF HUMAN RIGHTS}

\author{
ELIAS SAID-HUNG \\ Profesor titular \\ Facultad de Educación. \\ Universidad Internacional de la Rioja. \\ Calle Santa María de la Cabeza 5, 3ª. Majadahonda, Madrid \\ CP 28220 \\ TIfn: + 34692959503 \\ Email: elias.said@unir.net
}

\section{PALABRAS CLAVES}

Social media, Derechos Humanos, Participación Ciudadana, Medios, Democracia, Ciudadanía

\section{KEY WORDS}

Social Media, Human Rights, Citizen

Participation, Media, Democracy, Citizenship 


\section{Resumen}

Nos encontramos en medio de un proceso de transformación del proceso de comunicar y tener acceso a información, pero también en un momento donde el activismo ciudadano, la defensa de Derechos Humanos y la libertad de expresión, entre otros, han comenzado a sacar provecho de los social media para hacer frente a Estados Opresores, gobiernos populistas y organizaciones extremistas, por ejemplo. Si partimos de una visión universal del concepto de ciudadanía y del rol que debemos asumir en la defensa de temas de interés global como es la violación de los Derechos Humanos, muchas veces pierden trascendencia, ante la vorágine e inmediatez de la información que fluye desde los escenarios digitales actuales. Hecho que contribuye a la pérdida de interés o atención ciudadana de sucesos que favorecen la pérdida de Derechos Humanos, como resultado de una falta o inexistencia de soluciones que ayuden a formar una memoria digital colectiva global que permita recopilar, acceder y monitorizar a contenidos validados sobre este tipo de temas para su seguimiento ciudadano, en especial, y de los diferentes actores sociales interesados en ello (academia, medios de comunicación, periodistas y ongs, por ejemplo). La presente propuesta estará orientada en mostrar una estrategia que contribuya a la recolección y seguimiento de denuncias de violación de derechos humanos a nivel mundial.

\section{Abstract}

We are in the midst of a process of transformation of the process of communicating and having access to information, but also at a time when citizen activism, the defense of Human Rights and freedom of expression, among others, have begun to take advantage of the social networks to face the Oppressor States, populist governments, and extremist organizations, for example. If we start from a universal vision of the concept of citizenship and we must assume in the defense of issues of global interest such as the violation of Human Rights, they often lose significance, in the vortex and immediacy of the information that flows from the current digital scenarios. The fact that contributes to the loss of interest or citizen attention of events that favor the loss of Human Rights, because of a lack or lack of solutions that help to form a global collective digital memory that allows collecting, access and monitor validated content. This type of topics for its citizen follow-up, in particular, and of the different social actors interested in it (academia, media, journalists, and NGOs, for example). The present proposal will be oriented towards showing a strategy that contributes to the collection and follow-up of complaints of human rights violations worldwide. 


\section{Introducción}

Como bien apunta Kucharski (2016) con el triunfo de Trump y la victoria de la opción de salir el Reino Unido de la Unión Europea, trajeron consigo un aumento en el debate sobre el impacto que generando las noticias falsas (fakenews) y el "efecto eco" que de los social media en las sociedades (Williamson, 2016). Un hecho que ha dado pie el retomar conceptos como el de "posverdad" para dar cuenta del momento actual donde nos encontramos envueltos. Un concepto que no es nuevo, sino que surge a principios de la década de 1990 para dar cuenta a la información o conjunto de aseveraciones que no están basadas en hechos objetivos, sino que apelan, fundamentalmente, a emociones, creencias o deseos latentes en el público (espectador) (Tesich, 1992; Marzal, \& Casero-Ripollés, 2017).

Nos encontramos bajo un escenario mediático, marcado por el creciente dominio que están teniendo los social media como fuentes de noticias, a la hora de estructurar la opinión pública y de "transmitir" contenidos no contrastado a un número elevado de individuos, quienes se han convertido en "seres de acogida y transmisores" de contenidos, en su mayoría no contrastado o verificado, que comparten a través de sus contactos (redes), sin percatarse del potencial impacto que ello puede traer consigo a nivel social global (Valadier, 2017). Un escenario actual, donde la Ley de Brandolini1 pareciera cobrar una creciente vigencia (Williamson, 2016), ante la creciente hipertrofia comunicativa que han traído consigo el auge de los escenarios digitales actuales (social media), y la desrealización del mundo, donde lo real termina existiendo por voluntad del signo y la profusión de las imágenes ayudan a la promoción de la sociedad del espectáculo (Baudrillard, 1997).

La "infoxicación" en la que nos encontramos expuestos en la actualidad, no solo ha generado dificultad a la hora de procesar críticamente la avalancha de información que solemos tener acceso a diario2, sino una pérdida de sensibilidad a momento de responder asertivamente ante la sobreexposición de información violenta que han encontrado en los social media y aplicaciones de mensajería instantánea, vías para su viralización. Algo que puede traer consigo un marco de asimilación de dichos actos violentos como "normales", cuando no lo son, o sencillamente una pérdida de sentido ciudadano, a la hora de expresar su rechazo ante tales acciones, por ejemplo. Ello, sin contar la falta de capacidad crítica en la labor de contrastar la información que suele recibir una persona diariamente, lo cual reduce la posibilidad de reconocimiento que muchos tienen de reconocer lo que es veraz de lo que no lo es o lo que es lo mismo, de reconocer un buen "entrecot" de una "comida rápida".

El escenario descrito hasta ahora nos hace ubicarnos en una sociedad en la que sus miembros, pese a disponer una amplia (y en constante expansión) diversidad de recursos digitales para el acceso, gestión y verificación de la información, la mayoría son incapaces de afrontar, exitosamente, la tarea de hacer un uso efectivo de todo el "arsenal" del que disponen para tales fines. Algo que exige la promoción de desarrollos tecnológicos orientados a integrar soluciones ya existentes para que las personas, puedan tener acceso a mecanismos de participación ciudadana digital, así como de información validada colectivamente de hechos 
de interés humano, acontecidos tanto a nivel local, nacional, regional como a nivel internacional. Algo que también incidiría en el ejercicio de profesiones y actores instituciones vinculados a sectores avocados al cubrimiento, análisis o monitoreo de este tipo de información.

Nos encontramos en medio de un proceso de transformación del proceso de comunicar y tener acceso a información, pero también donde el activismo ciudadano, la defensa de Derechos Humanos y la libertad de expresión, entre otros, pudiesen sacar provecho de los social media para hacer frente a Estados opresores, gobiernos populistas y organizaciones extremistas, por ejemplo. Pero, más allá de las posibilidades que pueden brindar los social media y las aplicaciones móviles para fines de interés social, ¿Cuántas veces solemos estar expuestos a información falsa que nos llega a través de los social media o mensajería instantánea? ¿Cuántos de nosotros somos capaces de reconocer lo que es o no veraz entre tantos mensajes y contenidos que recibimos diariamente? ¿Cómo promover un espacio orientado a crear consciencia de la necesidad de defender temas de interés universal como son es la defensa de los Derechos Humanos, por ejemplo, bajo el escenario descrito hasta ahora? ¿Cómo reducir el estrés y sensación de saturación o insensibilidad ante la recepción de contenidos que deberían llamarnos a actuar solidariamente, de forma universal, pero que solemos mostrarnos escépticos o incrédulos ante las dudas fundadas de su veracidad? ¿Qué pasa con toda esa información veraz que suele "perderse" entre tal caos informativo que solemos convivir diariamente, a través de las diferentes aplicaciones que tenemos instalados en nuestros dispositivos móviles? Estas preguntas son solo alguna de las interrogantes que dan pie a esta propuesta, en especial, si partimos de una visión universal del concepto de ciudadanía y del rol que debemos asumir en la defensa de temas de interés global como es la violación de los Derechos Humanos, los cuales muchas veces, pierden trascendencia ante la vorágine e inmediatez de la información que fluye desde los escenarios digitales actuales (e.g. Caso de Aylan, el niño sirio encontrado muerto en una playa de la isla griega de Kos, como resultado de la ola de refugiados que tuvieron que dejar su país de origen ante el estado de guerra allí existente). Hecho que contribuye, muchas veces, a la pérdida de interés o atención ciudadana de sucesos que favorecen la pérdida de Derechos Humanos, como resultado de una falta o inexistencia de soluciones que ayuden a formar una memoria digital colectiva global que permita recopilar, acceder y monitorizar a contenidos validados sobre este tipo de temas para su seguimiento ciudadano, en especial, y de los diferentes actores sociales interesados en ello (academia, medios de comunicación, periodistas y ongs, por ejemplo).

Es lo hasta ahora expuesto que conviene reflexionar sobre el marco comunicativo actual y su consiguiente impacto en el abordaje de temas de interés social de carácter universal, como son los derechos humanos, así como la necesaria promoción de una nueva generación de herramientas que ayuden al aumento de la reflexión y análisis de hechos acontecidos en su entorno (local y global), que favorezca el desarrollo de una participación ciudadana que cuente con la capacidad de construir un relato más complejo de la realidad que le rodea. 


\section{El afecto como estrategia viral y el Fake News}

El escenario actual nos marca un contexto social donde lo real resulta evanescente, ante la actualización constante de contenidos que son recibidos por los individuos desde sus diferentes dispositivos tecnológicos y redes sociales (Valadier, 2017). Hecho que trae consigo que la opinión pública, muchas veces, esté basada en "realidades simuladas" que son aproximadas por muchos a través de las pantallas de móviles o de ordenadores, a distancia; donde lo imaginario fascina sobre la realidad efectiva.

La creciente transformación de los movimientos sociales y políticos, como resultado de los avances tecnológicos, no solo han generado fenómenos como "la Primavera Árabe", el "15M", "YoSoy132" u otros; también han contribuido a la transformación de los regímenes de percepción y la transformación de la esfera pública y de la democracia, y por ende, donde se desenvuelve nuestra vida cotidiana (Arias, 2016). Algo, donde la creciente digitalización y el aumento de la afectividad, desde los medios sociales actuales, nos están llevando a una sociedad sentimentalizada y viral, donde la exuberancia informativa, expuesta por autores como Chadwick (2009), está generando desequilibrio en los sistemas de decisión que muchos de los ciudadanos aplican para percibir la realidad y la forma como se desenvuelven en ellas. Donde la razón (lento y preciso) pareciera ir cediendo terreno a las emociones (rápido e intuitivo) (Kahneman, 2011). Lo que incide a la hora de determinar qué es políticamente significativo y lo que no.

La digitalización de la esfera pública, es decir, de los espacios donde gobiernos y ciudadanos intercambian ideas de asuntos públicos, están marcadas por un aumento de la sentimentalización de la democracia, donde se exacerba lo afectivo sobre lo racional o contrastado. Ello, de la mano de un creciente aumento del rol de co-protagonista que adquieren los ciudadanos en la construcción de opinión pública, desde los diferentes espacios digitales que hoy hacen parte activamente, desde lo expresivo y reactivo (el halago o descalificación de lo que acontece a su alrededor), y no desde lo deliberativo o reflexivo (Han, 2013; Arias, 2016).

Más que fomentar un marco de deliberación informada, los social media ejercen una función amplificadora y moduladora del estado de ánimo público, donde los diferentes actores sociales (individuales y colectivos) participan activamente desde la sobreabundancia de información y un contexto comunicativo altamente competitivo, al momento de generar atención en una audiencia y medios cada vez más fragmentados (Blumler, 2013). Por tanto, el contexto actual estaría caracterizado por un acelerado proceso de adaptación de los actores políticos y sociales a la lógica impuesta desde los medios digitales actuales (Strömbäck, 2008). Todo en busca de una mayor atracción de ciudadanos a sus opiniones (doxai), a los intereses que estos puedan tener en relación con determinados hechos. Esto, desde la apelación emotiva que centra, la mayor de las veces, los espacios comunicativos actuales, en especial los social media, donde se ha venido acrecentando la incapacidad que muchos ciudadanos tienen al momento tomar fragmentos de hechos que encajan entre sí y que favorecen a una comprensión mejor del contexto social que les rodea (Lepore, 2016).

Tal como se ha venido exponiendo, por autores como Gottfried y Shearer (2016) y Oremus (2016), 
el porcentaje de usuarios de los social media que emplean estos escenarios digitales como únicas fuentes de noticias ha venido creciendo progresivamente en los últimos años. Bajo este contexto, las posibilidades de tener contacto con noticias falsas (fake news) han aumentado exponencialmente, aprovechando los principales rasgos que caracterizan a este tipo de escenarios digitales: su capacidad de interacción y transmisión (compartir) contenido rápidamente, entre usuarios.

Si tomamos en consideración lo expuesto por Silverman (2016a, 2016b), en lo que se refiere a la interacción en usuarios de Facebook con noticias falsas a lo largo de las elecciones de Estados Unidos (figura 1) y de aquellas con mayor repercusión en esta red social durante 2016 (figura 2), logramos observar cómo nos encontramos bajo un escenario donde los ciudadanos están sobre expuestos a un alto número de contenidos no contrastados que terminan viralizándose y generando una opinión pública deformada de la realidad abordada y habitada por estos. Algo que queda en evidencia si tenemos en cuenta resultados obtenidos en proyectos realizados por la Universidad de Oxford (2017) y autores como Hazard (2017), al momento de destacar el porcentaje de contenido falso compartido por usuarios de social media como Facebook o microblogs como Twitter, durante la aprobación del Brexit en el Reino Unido y en votantes de Michigan, durante las elecciones en Estados Unidos3.

\section{Total Facebook Engagements for Top 20 Election Stories}

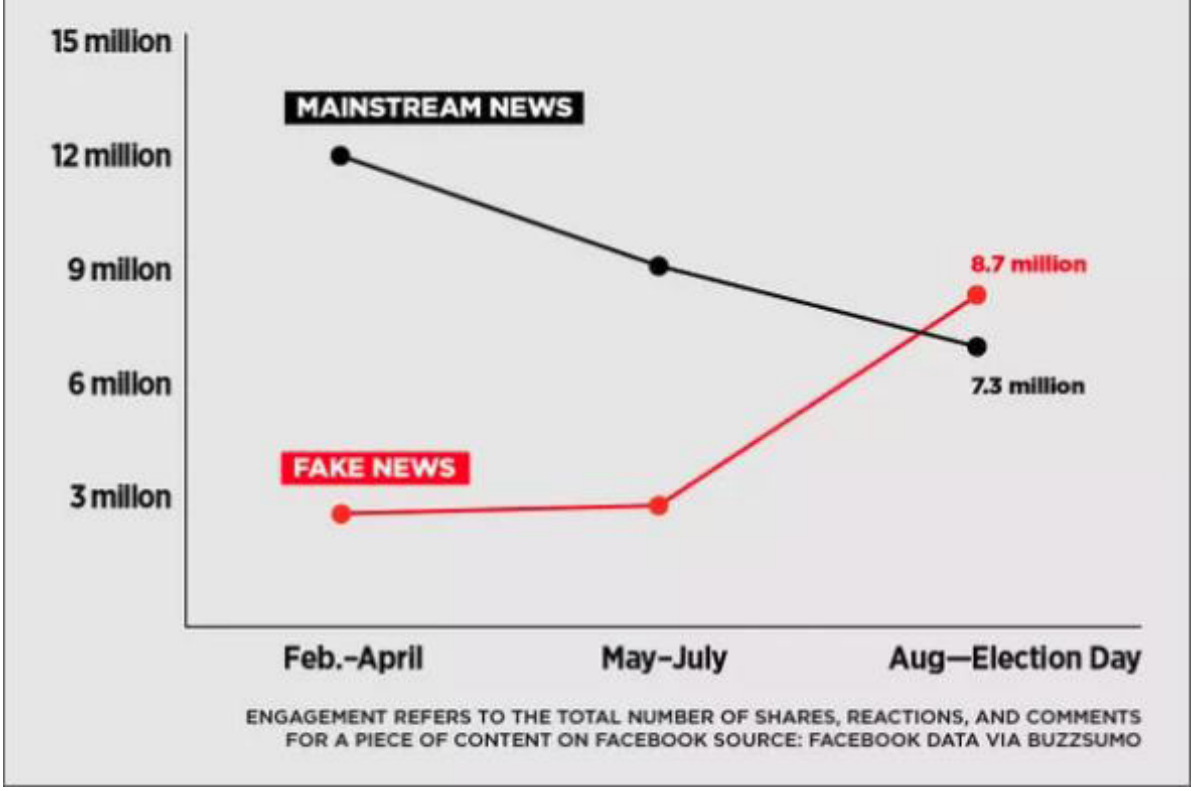

Figura 1. Número de compromisos generados por las principales 20 noticias divulgadas en Facebook, durante las elecciones en Estados Unidos de 2016. Fuente: https://www.buzzfeed.com/craigsilverman/viral-fake-election-newsoutperformed-real-news-on-facebook?utm_term=.tjPvy4V25w\#.ux6L0QPn6M 


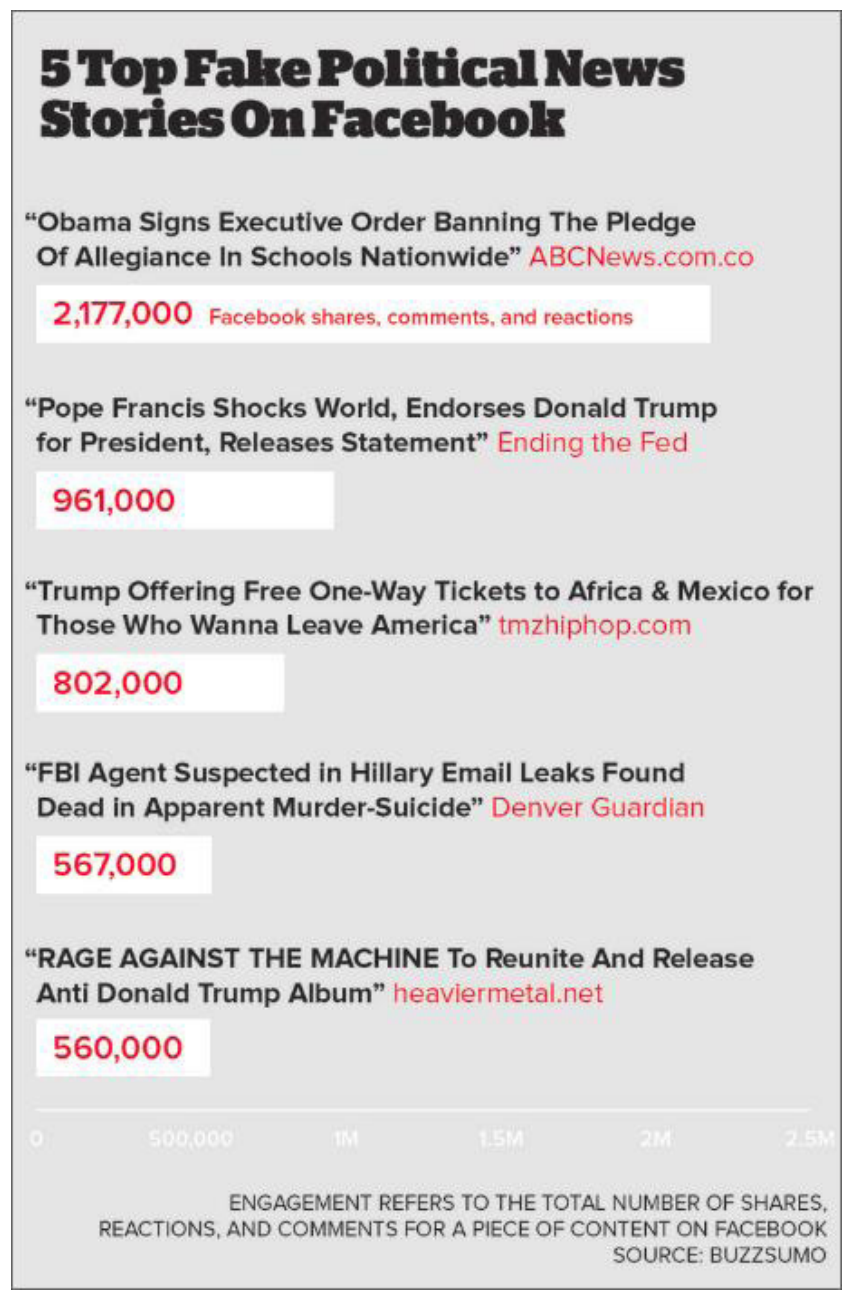

Figura 2. Principales noticias falsas compartidas en Facebook durante 2016. Fuente: https://www.buzzfeed.com/ craigsilverman/top-fake-news-of-2016?utm_term=.btMAw15mLY\#.pqPAYykv7K

Bajo el escenario hasta ahora descrito, lo afirmado por autores como Requeijo (2017), a la hora de dar cuenta de la proliferación de noticias falsas que contribuyen a la interpretación y toma de decisiones erróneas a nivel social, resulta relevante. Sobre todo cuando políticos apelan a sentimientos para atraer (conectar) potencial electorado y el modelo de negocio del sector comunicativo parece estar regido por la búsqueda de cliks y la tiranía del algoritmo, que personaliza el contenido que cada usuario recibe en su diferentes social media (Urmeneta, 2016; Arrese, 2016; Viner, 2016). Todo ello enmarcado en un marco social contemporáneo caracterizado por una creciente pérdida de autoridad de los medios como institución cultural del conocimiento, en manos de los mayores niveles de credibilidad que estaría ganando nuestros contactos en cualquiera de los social media donde nos encontramos (Boczkowski, 2016). Algo que estaría contribuyendo al aumento de los niveles de hemofilia y segregación observados en las orientaciones políticas (Gruzd, \& Roy, 2014), expresados en los mensajes publicados en los escenarios digitales, los cuales son compartidos por usuarios que poseen posiciones ideológicas similares (Blumler, 2013; Daykin, 2016). Ello, bajo la hiper-inmediatez de los mensajes publicados y transmitidos en los social media (Elmer, 2013). Lo que favorecería a la fragmentación den conocimiento y una falta de visión completa de la realidad que les rodea, o lo que es lo mismo el aumento del efecto "burbuja de filtro", indicado por Viner (2016) y la pérdida de frontera 
entre lo que es verdadero y falso, así como de lo que resulta una opinión de conocidos (amigos) y lo que es una noticia, y entre lo que es importante y lo que resulta irrelevante (Rohgalf, 2017).

\section{Medios de comunicación y construcción de realidades}

Los medios de comunicación, en su sentido más general, ejercen un papel preponderante a la hora de construir las realidades sociales, en especial a nivel político. Ello, desde la generación de un marco de pensamiento que representa el momemtum simbólico de la actualidad de nuestras sociedades contemporáneas (Rincón, 2006). Por tanto, las diferentes narrativas que circulan desde los diferentes medios de comunicación a los que accedemos, contribuyen a la construcción de las diferentes realidades, individuales y colectivas, que nos rodea.

Con el auge de los social media, vivimos en un momento donde la competencia y problemas económicos del modelo de comunicación tradicional han contribuido a la búsqueda de nuevos modelos de financiamiento, basado en la construcción de contenidos publicitarios y en una exacerbada búsqueda de mecanismos que ayuden a atraer el mayor número de lectores a sus diferentes páginas web (Carrillo, 2013; Viner, 2016). Un contexto que ha favorecido la producción de contenido chatarra (junk-food), orientado a la caza de clicks, desde la repetición y búsqueda de contenidos que impacten bajo la lógica del entretenimiento y el espectáculo de la sociedad contemporánea (Rincón 2006; Urmeneta, 2016).

El contexto comunicativo actual se encuentra regido por la construcción y reconstrucción que hacen los medios de comunicación (tradicionales y digitales) de diferentes temas y actores políticos. Todo con el fin de "ganar adeptos", alrededor de estos (Gayà, 2015). Algo que incide negativamente en el interés de lo que realmente puede resultar significativo o de interés público.

Como bien apunta Rincón (2006), bajo el mando de la posverdad, los discursos creados por muchos políticos y medios de comunicación están regidos por criterios orientados a la autoreferencialidad, el flujo permanente información, el estilo absoluto, la presencia constante de celebridades que hacen parte de las narrativas que fluyen constantemente desde los social media y medios digitales, la fragmentariedad de realidades, la reiteración de contenidos, la búsqueda constante del espectáculo, así como la construcción de vínculos con los usuarios. Todo ello, integrado desde el creciente sensacionalismo, superficialidad y emotivismo que rige los escenarios comunicativos en la actualidad, en especial desde los social media. Por tanto, nos ubicamos bajo un horizonte regido por un constante y abrumador "ruido digital" y una pérdida de peso de los medios de comunicación como autoridad informativa y moral. Algo que incide negativamente en la dotación de significados al ciudadano, a la hora de tomar las mejores decisiones y de entender mejor el mundo que le rodea y hace parte (Boczkowski, 2016).

La abundancia informativa actual, dominada por demasiadas fuentes de información y métodos de análisis, han generado una pérdida de referentes de autoridad que puedan ser reconocidos como intérpretes de la complejidad comunicativa que hoy tenemos ante nosotros (Arrese, 2016). Un contexto donde el ciudadano, 
muchas veces, termina asumiendo sus espacios personales de información, ubicados en las diferentes redes sociales en los que hace parte, como único medio que le permite hacer frente al universo informativo actual.

El escenario delineado hasta ahora, lleva la necesidad de reflexionar y debatir sobre el rol asumido por los medios digitales y el periodismo, en especial, en torno a la búsqueda de mecanismos que fortalezcan el control alrededor de las noticias falsas a los que nos encontramos expuestos en la actualidad. Una realidad que autores como Kovach y Rosentiel (2003), Zarzalejos (2017), Harding (2017) y organizaciones como el Ethical Journalism Network (2016), el Poynter Institute (Krueger, 2016), The Guardian Project (2017), la Organización de las Naciones Unidas, et al. (2017), el Instituto Reuters (Fundación Nuevo Periodismo Iberoamericano, 2017) o el Harvard Kennedy School (2017) han venido recopilando y promoviendo un conjunto de recomendaciones, protocolos de actuación y el desarrollo de recursos orientados a mejorar los procesos de verificación de la información que recibimos desde los social media y para retomar la bases fundamentales de la información. Algo que ayudaría a minimizar el impacto de este tipo de noticias en los medios de comunicación y social media, desde el ejercicio periodístico y la participación ciudadana. En especial, a la hora de verificar la información que se accede desde los escenarios digitales actuales y al momento de hacer parte de la viralización de este tipo de noticias. Todo esto, desde:

- Por un lado, la búsqueda de nuevos modelos de negocio donde, si bien resulta importante emplear el lenguaje de los usuarios de los social media, también se requiere la comprobación de datos y hechos, como alternativa ante el tsunami informativo que hoy debemos afrontar todos, sin distinción alguna (Beckett, 2017; Harding, 2017).

- Por el otro, favorecer las condiciones que ayuden a una mejora de la alfabetización mediática que los individuos (ciudadanos) cuentan en la actualidad, a la hora de distinguir noticias verdaderas y falsas (Beckett, 2017).

\section{De la democracia de enjambre a la democracia monitorizada}

En los últimos años ha venido creciendo la posición de investigadores que se muestran críticos al momento de dar cuenta del impacto que traen consigo los avances tecnológicos, a favor de la transparencia, la rendición de cuentas y los procesos democráticos (Davies y Bawa, 2012; Yu, \& Robinson, 2012; Fuch, 2014; Treré, 2016). Pese al énfasis que hemos hecho muchos investigadores, sobre el análisis de las oportunidades que brindan las plataformas sociales actuales a los ciudadanos, el advenimiento de fenómenos como el Big Data, entendido como el análisis de "cantidades masivas de información producidas por y sobre las personas, las cosas y sus interacciones" (Boyd, \& Crawford, 2012, p. 1), ha traído consigo, no solo, nuevos procesos de control, discriminación y exclusión, por parte de empresas e instituciones estatales que han venido aprovechando los datos generados desde las plataformas digitales actuales, a la hora de ejercer la vigilancia sistemática e invadir nuestra privacidad (Van Dijck, 2014; Lyon, 2014); sino también la aparición de nuevos actores informativos, relacionados con la sociedad civil, quienes promueven el acceso de datos, así como el desarrollo de repositorios o plataformas de información públicas (Casero-Ripollés, \& López-Meri, 
2014; Mayer-Schoenberger, \& Cukier, 2013).

Como bien apuntan autores como Bimber (1998), Berry, Kim y Spigel (2010), Arias (2016), la pluralización digital que vivimos en la actualidad no resulta necesariamente democratizadora, a pesar de la visibilidad que se dan de voces y movimientos sociales que irrumpen desde los espacios de convergencia emocional que surgen desde los social media. Un contexto que favorece la promoción de lo que autores como Han (2013) han dado en llamar "democracia de enjambre", o lo que es lo mismo, la suma de un número significativo de individuos que reaccionan a base de halagos y descalificaciones que irrumpen y trascienden al espacio público.

Resulta cada vez más importante avanzar en el desarrollo de mecanismos que ayuden a canalizar, de forma más productiva a nivel social, la promoción de la repolitización de los ciudadanos, y la sensación participativa que muchos pueden estar sintiendo (Athique, 2013), desde la reacción afectiva de los contenidos que tienen contacto y retransmiten constantemente. Por ello, es clave la promoción de una nueva generación de recursos tecnológicos que aprovechen el Big Data, a la hora de potenciar un nuevo sistema democrático cada vez más monitorizado y ocular (Green, 2010; Arias, 2016),no regido únicamente desde lo afectivo, donde la ingente cantidad de datos que se generan desde las plataformas que empleamos para tomar contacto, producir y compartir contenido deberían servir más allá de los fines comerciales, sino también a la promoción de escenarios que contribuyan a la alfabetización mediática que aludíamos al final del apartado anterior, desde el nuevo lenguaje que impera en los escenarios digitales actuales, lo visual. Nos encontramos por tanto en bajo un contexto donde se requiere avanzar en la generación de mecanismos que ayuden a sacar productividad fiscalizadora del Big Data, para que periodistas, medios de comunicación, organizaciones de la sociedad civil y ciudadanos, en general, hagan un mayor seguimiento y control de los centros de poder políticos y económicos (Keane, 2009). Sobre todo cuando lo que parece estar siendo exaltado desde los escenarios digitales actuales es la participación directa del ciudadano y el "do it yourself", en el que se deslegitima, al menos de forma aparente, la mediación realizada por actores institucionales tradicionales (Morozov, 2013) y donde las concepción del poder patrimonial y vertical, se transforma por nuevas formas de poder (micropoder), las cuales sacan provecho de las tecnologías para coordinarse con sus miembros desde los escenarios digitales actuales (Naím, 2013).

\section{Derechos humanos, acción colectiva y social media}

Como bien apuntan autores como Tilly (2004), Hunt (2009) y Donelly (2011) los derechos humanos deben ser visto como un conjunto de pretensiones y reinvindicaciones morales y sociolíticas que, en los dos últimos siglos, han experimentado períodos de reconocimiento, como resultado de las diferentes luchas, conflictos sociales y transformaciones que ha experimentado las diferentes prácticas culturales y políticas ejercidas al interior de las sociedades occidentales. El reconocimiento de este tipo de derechos, a lo largo de todo este período, ha traído consigo la redefinición de las relaciones entre los ciudadanos y los Estados Nación, al ser los primeros los titulares de dichos derechos (de carácter universal), que van más allá de las soberanías ejercidas por los últimos. 
La acción colectiva alrededor de la defensa de los derechos humanos, además de poseer un carácter transnacional inherente, posee estructuras y un conjunto de recursos que permiten traducir en lenguaje jurídico a la búsqueda de objetivos colectivos desde el reconocimiento institucional de este tipo de derechos. Esto, sin dejar de lado la capacidad que tienen este tipo de derechos, a la hora de ser utilizados como acción política o recursos para la promoción de un conjunto de reinvindicaciones frente a otros actores; así como a la clara diferenciación que hay entre las organizaciones civiles y las instituciones de carácter oficial, que ejercen su defensa a nivel internacional, nacional y localmente (López, \& Hincapié, 2015).

Como señala López e Hincapié (2015), el reconocimiento, la socialización y la institucionalización que se ha experimentado alrededor de los derechos humanos, como principios normativos, han traído consigo una transformación de las relaciones entre los diferentes actores sociales a nivel global, a saber: los agentes internacionales, los gobiernos y los ciudadanos.

El estudio de los actores colectivos, garantes de los derechos humanos, a nivel de las Ciencias Sociales, se ha centrado en tres tipos:

- En primer lugar, desde la comprensión de los efectos que ejercen la presión internacional, de la mano con las organizaciones no gubernamentales, en el comportamiento de los Estados Nación sobre este tema (Risse, Ropp, \& Sikkink, 1999; 2013; Keck, \& Sikkink, 2000; Simmons, 2009).

- En segundo lugar, desde el uso subalterno de los derechos humanos por parte de los movimientos sociales y actores colectivos, donde las organizaciones no gubernamentales actúan como intermediarios y traductores de causas concretas (Merry, 2006; Santos, \& Rodríguez, 2007; Merry, \& Levitt, 2009).

- Y en tercer lugar, desde la imposición del "imperialismo moral" ejercido desde las organizaciones no gubernamentales, al momento de ejercer de garantes del conocimiento experto, en torno a dicha temática (Dezalay, 2003; Dezalay, \& Garth, 2005; Berkovitch, \& Gordon, 2008).

La aproximación conceptual que se ha hecho de los actores colectivos alrededor de los derechos humanos aún no ha ahondado, de forma exhaustiva, en el impacto que trae consigo los social media. En especial, a la hora de dotar al ciudadano (desde su plano individual de acción colectiva) de capacidad efectiva en la defensa de dichos derechos. Sobre todo, si nos encontramos en medio de un escenario digital global marcado por una abundancia informativa, un aumento progresivo de la divulgación desmesurada de noticias falsas, una pérdida de reconocimiento de lo que es o no verdadero, así como también la irrupción que hemos sido testigos en los últimos años de movimientos sociales a nivel nacional o internacional (e.g. Primavera Árabe, Ocuppy Wall Street, 15M, YoSoy132, SOSVenezuela, entre otros), y de un contexto social donde el aprovechamiento del Big Data exige la participación del mayor número de actores sociales al momento de verificar, desde sus diferentes perspectivas (testigo o experto), las diferentes violaciones que se llevan a cabo de este tipo de derechos en el mundo. Una acción que resulta inviable de llevar a cabo bajo el liderazgo de 
un único actor colectivo, sino desde la co-responsabilidad asumida por el mayor número de actores sociales.

Es bajo lo hasta ahora expuesto, que el rol asumido por los actores sociales, alrededor de la defensa de los derechos humanos, requiere de una revisión ante el actual proceso de digitalización que se vive al interior de nuestras sociedades contemporáneas. Un contexto donde los avances de las tecnologías y el auge de los social media se han convertido en uno de sus principales rasgos distintivos (Albaigès, 2007). Sobre todo si tenemos en cuenta lo expuesto por autores como Herrera (1998), Acevedo (2004), y Said-Hung y Valencia (2014), al dar cuenta del bajo nivel de uso y aprovechamiento de las tecnologías desde las organizaciones no gubernamentales, a la hora de divulgar y promover sus fines, así como promover mecanismos de deliberación y participación desde los escenarios digitales actuales con otros agentes sociales, y a favor de la generación de comunidades digitales. Todo ello, con el fin de contribuir al fomento de un escenario social orientado a la generación de materiales comunicables y de mecanismos de respuesta social, y acceso a información transparente, sin intermediación alguna (Cremades, 2007).

Lo hasta ahora expuesto ayudaría a dar mayor visibilidad, pero sobre todo más profundidad al trabajo realizado por muchas organizaciones no gubernamentales, cuya misión se centra en la defensa de los derechos humanos a diferentes niveles (local, nacional e internacionalmente). Sobre todo, a la hora de ahondar en la promoción de mecanismos que ayuden al registro, seguimiento y validación de casos de violación de este tipo de derechos en las diferentes áreas de acción donde ejercen dicha función (e.g. Anmistía Internacional, Reporteros Sin Frontera y Human Right Watch, entre otros). Algo que, no solo, requiere de conocimiento experto en el abordaje de dicha temática y correcta tipificación de las posibles violaciones; sino también la participación activa de una mayor número de ciudadanos, más allá de hacer visible, desde los social media y medios digitales actuales, este tipo de sucesos. Ello, en vista que la acción ciudadana individual pudiese contribuir también en la visibilidad de estos sucesos, al momento de registrarlos desde los diferentes dispositivos móviles a su alcance, pero también a la hora de sacar provecho a las dinámicas comunicativas y sociales promovidas desde los social media actuales. Una función que no necesariamente se podría llevar a cabo de forma independiente a la labor realizada a nivel de los actores colectivos tradicionales, sino que se ejecutaría como complemento individualizado, a nivel de cada uno de los usuarios-ciudadanos, movilizados desde lo emotivo y otros rasgos expuestos previamente.

Por tanto, nos encontramos en un momento donde resultaría muy importante exigir al conjunto de actores sociales interesados en la defensa de los derechos humano, desde los escenarios digitales actuales, la aplicación de estrategias y recursos que estén encaminados a fortalecer el conjunto de acciones colectivas puestas en marcha para el fomento de la cooperación en defensa de estos derechos, desde la responsabilidad de un mayor número de actores sociales a: la búsqueda la mejor eficiencia de acciones y de los recursos dispuestos para el cumplimiento de las misiones a cargo; la generación de mecanismos de control en el respeto de los derechos humanos, a todos los niveles o planos sociales; la generación de acciones colectivas más extensas en el alcance temporal y geográfico; y el aumento de las oportunidades a la hora de compartir, intercambiar y participar con un mayor número de actores sociales alrededor de este tema (Acevedo, 2004; 
2006).

\section{Conclusiones}

Como hemos podido observar, nos encontramos en un momento donde el aumento de fuentes de información y la capacidad que muchos ciudadanos tienen el creciente auge de los social media, si bien puede traer consigo escenarios deliberativos, de visibilidad de movimientos sociales y el surgimiento de nuevas formas de poder, ello no está exento de peligros latentes, bajo la abundancia informativa que hoy domina el escenario comunicativo actual. Un contexto que exige no solo, una posición más crítica (sin llegar a ser considerada apocalíptica), al momento de dar cuenta del impacto que traen consigo los avances tecnológicos, a favor de la transparencia, la rendición de cuentas y los procesos democráticos; sino también la búsqueda de estrategias que ayuden a promover un entorno social donde las recomendaciones hechas por autores como Kovach y Rosentiel (2003), Zarzalejos (2017), Harding (2017) y organizaciones como el Ethical Journalism Network (2016), el Poynter Institute (2016), The Guardian Project (2017), la Organización de las Naciones Unidas, et al. (2017), el Instituto Reuters (2017) o el Hardvard Kennedy School (2017) terminen contribuyendo a un uso articulado de medidas que sirvan a un amplio abanico de actores sociales interesados en visibilizar acontecimientos de interés público, como puede ser la defensa de los derechos humano.

Este trabajo centra su mirada en la necesidad de trascender la fragmentación de recomendaciones o acciones que buscan fines comunes a los temas planteados aquí. Ello, a través del desarrollo de recursos o soluciones tecnológicas donde la acción colectiva ejercida por organizaciones no gubernamentales, estatales, profesionales y ciudadanas, interesadas en la defensa de los derechos humanos, puedan ejercer mecanismos de participación efectiva para tales fines. Esto, desde la verificación de hechos que ayuden al registro, la curaduría, la validación, el registro y la preservación (exposición pública) de contenido relacionado con denuncias de violaciones de derechos humanos que puedan estar aconteciendo a nivel local, nacional, regional o globalmente. Algo que, si bien se está haciendo a nivel individual, desde muchas organizaciones no gubernamentales (e.g. Anmistía Internacional, Reporteros Sin Frontera y Human Right Watch, entre otros), el alcance del impacto de este tipo de acciones quedan muy limitados o restringidos a los recursos que este tipo de actores tienen para afrontar tal colosal tarea; mientras se sigue dejando a actores sociales relevantes (los ciudadanos) asumiendo roles eminentemente de denunciantes o replicadores de contenidos relacionados con el tema aquí tratado. Esto, a pesar que los avances tecnológicos y del Big Data, permitirían aprovechar más eficientemente los escenarios digitales actuales para generar un marco acción social donde expertos y ciudadanos puedan participar, desde sus roles y capacidades, en los diferentes eslabones requeridos para evitar que estos temas de interés públicos se pierdan entre tanta noticia falsa.

Lo aquí planteado no parte únicamente del proceso de reflexión mostrado a lo largo de este documento, sino del interés existente en aplicar la teoría y las potencialidades inherentes que hoy permiten los avances tecnológicos a la generación de soluciones, donde el mayor número de actores sociales pueden colaborar y participar activamente, en el estudio y visibilidad de hechos como los expuestos en el apartado introductorio de este trabajo, en el que dábamos cuenta de algunas preguntas que motivaron todo lo aquí expuesto y que, 
a fin de cuenta, lo que se busca es impulsar medidas que faciliten la tarea de evitar que el abrumador "ruido digital" que hoy tenemos que convivir no eclipse temas que deberían ser universales, como es la defensa de los derechos humanos, cuya violación no prescriben a nivel penal y donde hemos podido ver cómo un vídeo colgado en internet ha servido a la Corte Penal Internacional a juzgar a un terrorista de ISIS (Gutiérrez, 2017). Algo que requiere avanzar en el desarrollo de aplicaciones o soluciones tecnológicas que faciliten este tipo de decisiones y en el aumento del interés público de este tipo de temas a nivel social, más allá de la prevalencia con que suelen abordarse desde los social media y escenarios digitales actuales.

\section{Referencias}

- $\quad$ Acevedo, M. (2004). Las TIC en las políticas de cooperación al desarrollo: hacia una nueva cooperación en la Sociedad Red. Cuadernos internacionales de tecnología para el desarrollo humano, 2, 1-10.

- $\quad$ Acevedo, M. (2006). Integración de las tecnologías de la información y comunicación. Asignatura pendiente de la cooperación. Madrid: CONGDE.

- Albaigès, J. (2007). Usos y retos de las TIC en las organizaciones no lucrativas. Barcelona: Observatorio del Tercer Sector.

- $\quad$ Athique, A. (2013). Digital Media and Society. An Introduction. Cambridge: Polity.

- $\quad$ Arrese, A. (2016). Política post-factual y sociedad post-mediática. Nuevas Tendencias, 97, 8-14.

- $\quad$ Baudrillard, J. (1997). El otro por sí mismo. Barcelona: Anagrama.

- $\quad$ Beckett, C. (2017, Marzo 11). 'Fake news': the best thing that's happened to journalism. Obtenido en http://blogs. 1se.ac.uk/polis/2017/03/11/fake-news-the-best-thing-thats-happened-to-journalism/

- Berry, C., Kim, S., \& Spigel, L. (2010). Electronic elsewheres: Media technology and the experience of social space. Minneapolis: University of Minnesota Press.

- $\quad$ Berkovitch, N., \& Gordon N. (2008). The Political Economy of Transnational Regimes: The Case of Human Rights. International Studies Quarterly, 52(4), 881-904.

- $\quad$ Bimber, B. (1998). The Internet and political transformation: Populism, community, and accelerated pluralism. Polity, 31(1), 133-160. Doi: 10.2307/3235370.

- Blumler, J.G. (2013, Septiembre 17). The Fourth Age of Political Communication. Obtenido de http://www.fgpk.de/ en/2013/gastbeitrag-von-jay-g-blumler-the-fourth-age-of-political-communication-2/

- $\quad$ Boczkowski, P. (2016) Las noticias falsas y el futuro del periodismo. La posverdad. Revista Anfibia. Obtenido en http://www.revistaanfibia.com/ensayo/la-postverdad/

- $\quad$ Boyd, D., \& Crawford, K. (2012). Critical Questions for Big Data: Provocations for a Cultural, Technological, and Scholarly Phenomenon. Information, Communication and Society, 15(5), 662-79.

- $\quad$ Casero-Ripollés, A., \& López-Meri, A. (2015). Redes sociales, periodismo de datos y democracia monitorizada. Revista Latina de Comunicación Social. doi: 10.4185/cac92

- $\quad$ Carrillo, N. (2013). El género-tendencia del infoentretenimiento: definición, características y vías de estudio. En C. Ferré Pavia (Ed.), Infoentretenimiento: El formato imparable de la era del espectáculo (pp. 33-58). Barcelona, España: Editorial UOC.

- $\quad$ Chadwick, A. (2009). Web 2.0: New challenges for the study of e-democracy in an era of informational exuberance. Journal of Law and Policy for the Information Society, 5(1), 9-41. 
- $\quad$ Davies, T., \& Bawa, Z. (2012). The Promises and Perils of Open Government Data (OGD). Journal of Community Informatics. Obtenido en http://ci-journal.net/index.php/ciej/article/view/929/926.

- Daykin, J. (2016, Junio 28). Could social media be tearing us apart? The Guardian. Obtenido en https://www. theguardian.com/media-network/2016/jun/28/social-media-networks-filter-bubbles

- Desardins, J. (2017). What happens in an internet minute in 2017. World Economic Forum. Obtenido en https:// www.weforum.org/agenda/2017/08/what-happens-in-an-internet-minute-in-2017?utm_content=buffer7d0cfy utm_medium=socialy utm_source=facebook.comy utm_campaign=buffer

- Dezalay, Y. (2003). Las ONG y la dominación simbólica. En J. Beneyto (Ed.), Hacia una sociedad civil global (pp. 347-380). Madrid: Taurus.

- $\quad$ Dezalay, Y, \& Garth, B. (2005). La internacionalización de las luchas por el poder. La competencia entre abogados y economistas por transformar los Estados latinoamericanos. México: Universidad Nacional Autónoma de México-Instituto Latinoamericano de Servicios Legales Alternativos.

- Donelly, J. (2011). La construcción social de los derechos humanos. Relaciones Internacionales, 17(junio), 153-184.

- Elmer, G. (2013), Live research: twittering an election debate. New media \& society, 15(1). doi: $10.1177 / 1461444812457328$

- $\quad$ Ethical Journalism Network (2017). Report on Challenges for Journalism in the Post-truth Era , Ethics in the News. Obtenido en http://ethicaljournalismnetwork.org/wp-content/uploads/2017/01/ejn-ethics-in-the-news.pdf

- $\quad$ Cremades, J. (2007). Micropoder: La fuerza del ciudadano en la era digital. Madrid: Espasa-Calpe.

- $\quad$ Fuchs, C. (2014). Social Media: A Critical Introduction. Londres: Sage.

- $\quad$ Fundación Nuevo Periodismo Iberoamericano (2017). 11 recomendaciones del Instituto Reuters para no caer en noticias falsas. Obtenido en http://www.fnpi.org/es/etica-segura/11-recomendaciones-del-instituto-reuters-para-no-caer-ennoticias-falsas

- Gayà, C. (2015). El Periodismo de Interacción Social, una propuesta de dinamización del campo periodístico. (Tesis de doctorado). Barcelona: Universitat Autònoma de Barcelona.

- $\quad$ Gottfried, J., \& Shearer, E. (2016, Mayo 26). News use across social media platforms 2016. Pew Research Center. Obtenido en http://www.journalism.org/2016/05/26/news-use-across-social-media-platforms-2016/

- Green, J. (2010). The eyes of the people: democracy in an age of spectatorship. Oxford: Oxford University Press.

- $\quad$ Gruzd, A. and Roy, J. (2014). Investigating Political Polarization on Twitter: A Canadian Perspective. Policy \& Internet, 6(1). doi: 10.1002/1944-2866.POI354.

- Gutiérrez, I. (2017, Septiembre 22). ¿Sirve un vídeo colgado en la Red para juzgar un crimen de guerra? Obtenido en https://elpais.com/internacional/2017/09/15/actualidad/1505480519_096810.html

- Han, B. (2013). Im Schwarm. Berlín: Matthes and Seitz.

- $\quad$ Harding, P. (2017). Remember that facts are sacred. British Journalism Review, 28(1), 17-22.

- Harvard Kennedy School (2017). First Draft. Obtenido en https://es.firstdraftnews.com/

- Hazard, L. (2017, Junio 12) Brits and Europeans seem to be better than Americans at not sharing fake news. Nieman Lab. Obtenido en http://www.niemanlab.org/2017/06/brits-and-europeans-seem-to-be-better-than-americans-at-notsharing-fake-news/

- Herrera, M. (1998). La especificidad organizativa del tercer sector: tipos y dinámicas. Papers Revista de Sociología, 56, 163-196.

- Hunt, L. (2009). La invención de los derechos humanos. Barcelona: Tusquets. 
- Kahneman, D. (2011). Thinking, fast and slow. London and New York: Allen Lane.

- Keane, J. (2009). The life and death of democracy. London: Simon and Schuster.

- $\quad$ Keck, M., \& Sikkink, K. (2000). Activistas sin fronteras. Redes de defensa en política internacional. México: Siglo XXI Editores.

- $\quad$ Kovach, B.; \& Rosenstiel, T. (2003). Los elementos del periodismo (Traductor Diéguez Rodríguez, A.). Madrid, España: Santillana Ediciones Generales (2003).

- Kucharski, A. (2016). Post-truth: Study apidemiology of fake news. Nature, 540. Obtenido en https://www.nature. com/articles/540525a

- Krueger, V. (2016). 9 questions that help you verify information. Obtenido en https://www.poynter.org/news/9questions-help-you-verify-information

- Lepore, J. (2016, Marzo 21). After The Fact. Obtenido en www.newyorker.com/magazine/2016/03/21/the-internet-ofus-and-the-end-of-facts

- $\quad$ López. J., \& Hincapié, S. (2015). Campos de acción colectiva y las ONG de derechos humanos. Herramientas teóricas para su análisis. Sociológica, 30(85), 9-37.

- Lyon, D. (2014). Surveillance, Snowden, and Big Data: Capacities, Consequences, Critique. Big Data and Society, $1(1), 1-12$.

- $\quad$ Mayer-Schoenberger, V., \& Cukier, K. (2013). Big Data. A Revolution That Will Transform How We Live, Work, and Think. Londres: John Murray Publishers.

- Merry, S. (2006). Transnational Human Rights and Local Activism: Mapping the Middle. American Anthropologist, 108(1), 38-51.

- $\quad$ Merry, S., \& Levitt, P. (2009). Vernacularization on the Ground: Local Uses of Global Women's Rights in Peru, China, India and the United States. Global Networks, 9(4), 441-461.

- $\quad$ Morozov, E. (2013). To Save Everything, Click Here. Technology, solutionism and the urge to fix problems that don't exist. London: Allen Lane.

- $\quad$ Naím, M. (2013). The End of Power. From Boardrooms to Battlefields and Churches to States, Why Being In Charge Isn't What It Used to Be. New York: Basic Books.

- $\quad$ Organización de las Naciones Unidas (2017). Declaración conjunta sobre libertad de expression y "noticias falsas" ("Fake News"), desinformación y propaganda. Estados Unidos: Organización de Estados Americanos. Obtenido en http://www.oas.org/es/cidh/expresion/showarticle.asp?artID=1056\&lID=2

- $\quad$ Oremus, W. (2016, Diciembre 20). How Many People Really Get Their News From Facebook? Obtenido en http:// www.slate.com/articles/technology/technology/2016/12/how_many_people_really_get_their_news_from_facebook.html

- Requeijo, A. (2017, Marzo 11). La noticia del Washington Post. El Español. Obtenido en http://www.elespanol.com/ opinion/tribunas/20170310/199850016_12.html

- $\quad$ Rincón, O. (2006). Narrativas mediáticas. O cómo se cuenta la sociedad del entretenimiento. Barcelona, España: Gedisa.

- $\quad$ Risse, T., Ropp, S., \& Sikkink, K. (2013). The Persistent Power of Human Rights: From Commitment to Compliance. Cambridge: Cambridge University Press.

- $\quad$ Risse, T., Ropp, T., \& Sikkink, K. (1999). The Power of Human Rights: International Norms and Domestic Change. Cambridge: Cambridge University Press.

- $\quad$ Said-Hung, E., \& Valencia, J. (2014). El uso de las redes sociales en las ONGS Inmigrantes en España. Sociedade e Cultura, 17(2). doi: 10.5216/sec.v17i2.22925 
- $\quad$ Santos, B., \& Rodríguez, C. (2007). El derecho y la globalización desde abajo. Hacia una legalidad cosmopolita. Barcelona: Anthropos.

- $\quad$ Silverman, C. (2016a, Noviembre 16). HThis analysis shows how viral fake election news stories outperformed real news on facebook. Obtenido en https://www.buzzfeed.com/craigsilverman/viral-fake-election-news-outperformed-real-newson-facebook?utm_term=.kiMxv82MX\#.bdz6XGOE5

- $\quad$ Silverman, C. (2016b, Diciembre 30). Here are 50 of the biggest fake news hit on Facebook from 2016. Obtenido en https://www.buzzfeed.com/craigsilverman/top-fake-news-of-2016?utm_term=.mgy0qQaNj\#.grKNyGzaX

- $\quad$ Simmons, B. (2009), Mobilizing for Human Rights: International Law in Domestic Politics. Cambridge: Cambridge University Press.

- Strömbäck, J. (2008). Four phases of mediatization: An analysis of the mediatization of politics. The international journal of Press/politics, 13(3). doi: 10.1177/1940161208319097

- $\quad$ Tesich, S. (1992, Enero 6). A Government of Lies. The Nation, 12-14.

- Treré, E. (2016). Distorsiones tecnopolíticas: repression y resistencia algorítmica del activismo ciudadano en la era del 'Big Data'. Trípodos, 39, 35-51.

- The Guardian Project (2017). Obtenido en https://guardianproject.info/

- $\quad$ Tilly, Ch. (2004), ¿De dónde vienen los derechos? Sociológica, 55(19), 273-300.

- Universidad de Oxford (2017). The computational propaganda Project. Obtenido en http://comprop.oii.ox.ac.uk/

- Urmeneta, M. (2016, Octubre 10). Bienvenidos a la Era de la posverdad. Aceprensa. Obtenido en http://www. aceprensa.com/articles/bienvenidos-la-era-de-la-posverdad/

- Valadier, P. (2017). La posverdad, peligro para la democracia. Revista de Fomento Social, 72(2), $297-304$.

- Van Dijck, J. (2014). Datafication, Dataism and Dataveillance: Big Data between Scientific Paradigm and Ideology. Surveillance and Society, 12(2), 197-208.

- Viner, K. (2016, Julio 12). How technology disrupted the truth. The Guardian. Obtenido en www.theguardian.com/ media/2016/jul/12/how-technology-disrupted-the-truth

- Williamson, P. (2016). Take the time and effor to correct misinformation. Nature, 540. Obtenido en https://www. nature.com/news/take-the-time-and-effort-to-correct-misinformation-1.21106

- $\quad$ Yu, H.. \& Robinson, D. (2012). The New Ambiguity of Open Government. UCLA Law Review Discourse, 178. Obtenido en http://www.uclalawreview.org/the-newambiguity-of-\%E2\%80\%9Copen-government\%E2\%80\%9D/>.

- Z Zarzalejos, J.A. (2017). Comunicación, periodismo y 'fact-checking'. UNO, 27, 11-13.

1 La ley enuncia que "La cantidad de energía necesaria para refutar una estupidez es un orden de magnitud mayor que para producirla"

2 De acuerdo con un artículo publicado por Jeff Desjardins, editor de Visual Capitalist, cada 60 segundos en 2017: se envían 452k tweets, se hace 3,5 millones búsquedas en google, se envían 156 millones de correos electrónicos, se ven 4,1 millones de vídeos en Youtube y enviados 16 millones de mensajes de texto a través de whatsapp, entre otros datos. Para más información: https://www.weforum.org/agenda/2017/08/what-happens-inan-internet-minute-in-2017?utm_content=buffer7d0cfy

3 En el caso de las elecciones en el Reino Unido los usuarios llegaros a compartir un 11,4\% de contenido falso, de acuerdo con el proyecto realizado por la Universidad de Oxford; mientras que los votantes de Míchigan, llegaron a compartir un 33\%, durante las elecciones de Estados Unidos, según el proyecto realizado por Hazard. 